\title{
Lesiones distróficas y carcinoma in-situ del cervix
}

\author{
Doctores G. López_Escobar y Santiago Leaño F.
}

El cáncer del Cervix Uterino es causa frecuente de mortalidad y en nuestro medio su incidencia es elevada y superada únicamente por el cáncer de la piel. De ahí la importancia y la gravedad que encierra el problema de su estudio bien sea que se trate de un estado de franca invasión o de un estado todavía intra-epitelial, in-situ o estado O; gravedad que comparten las distrofias del cuello uterino sobre todo aquellas que pueden ser consideradas como lesiones sospechosas susceptibles de evolucionar hacia un estado de malignidad verdadera. Gravedad e importancia que se destaca si recordamos que el tratamiento del carcinoma intraepitelial debe darnos un ciento por ciento de curacio_ res, cosa que no sucede cuando el carcinoma es francamente invasor, y si consideramos el notable papel de profilaxis que pudiera desempeñar el ginecólogo si lográramos determinar con certeza cuáles de estas lesiones distróficas cervicales son verdaderamente premalignas (1).

Desafortunadamente el carcinoma in-situ lo mismo que las distrofias, es de sintomatologia tan silenciosa que la mujer atacada no presta importancia a ella, o si consulta al médico, bien puede ser éste quien no sospeche siquiera que la mujer que le consulta está gravemente amenazada.

Todas estas consideraciones han contribuido a este trabajo recopilando las ideas más frescas de la medicina actual y para cuya realización se han estudiado más de 600 biopsias del cuello uterino en los Laboratorios de anatomía patológica del Instituto Nacional de Cancerología de Bogotá. Se ha insertado también en FICS.

(*) Profesor Agregado de Ginecología de la Universidad Nacional. FACS

(**) Del Instituto Nacional de Cancerología. En parte este trabajo sirvió como tema de tesis del doctor Leaño $\mathrm{F}$. 
este trabajo la investigación del glucógeno en las lesiones distróficas y el carcinoma in-situ y su valoración en el diagnóstico histopatológico teniendo en cuenta que la ausencia o desaparición del glucógeno del epitelio puede ser un indicio do malignidad.

El Epitelio del Cuello Uterino: (4-5-9) Como es bien sabido el epitelio del cuello uterino es de dos tipos: escamoso estratificado y epitelio glandular. La "pars vaginalis" que hace protrusión dentro de la vagina está cubierta por un epitelio esencialmente similar al epitelio estratificado de la vagina, aunque las papilas sub-epiteliales son mucho menos marcadas y pueden estar ausentes. Este epitelio se caracteriza por un conjunto ordenado de capas. La más profunda: capa basal o stratum germinativum o stratum cylindricum está compuesta de células con poco citoplasma y núcleos hipercromáticos alargados, en forma de empalizada, perpendicular al estroma subyacente. Por encima de esta capa, en los estratos siguientes, a medida que las células se hacen más superficiales: aumentan su citoplasma, se cargan de glucógeno, se aplanan; el núcleo disminuye de tamaño, se horizontaliza, se hace picnótico y aun desaparece en las capas superficiales; los puentes intercelulares visibles en las capas profundas desaparecen o se hacen menos visibles. La capa superficial o zona de descamación similar al stratum corneum de la piel, normalmente no muestra cornificación a no ser que el cuello uterino esté expuesto como resultado de un prolapso, al ambiente exterior, caso en el cual se cornifica volviéndose casi como la piel.

El epitelio del endocervix de características completamente diferentes es cilíndrico, uniestratificado, sin cilias y con glándu. las en tridente. Estas glándulas no se encuentran en el cuello :terino del feto, pero ya a los cinco años se encuentra un esbozo de ellas, como lo pudimos comprobar en los cortes histológicos del cuello uterino de una niña de esta edad (Figura N. I. y I A y I B).

El epitelio pavimentoso estratificado del exocervix se extien. de hasta cerca del orificio externo, pero las variaciones individuales a este respecto son notorias siendo la línea de demarcación frecuentemente un poco más distal o más proximal al orificio. La transición entre uno y otro epitelio es por lo general bastante brusca, pero existe una gran diversidad en las modalidades de esta transición debidas a procesos inflamatorios, o de reparación, etc.

Glucógeno del Epitelio.-De todo ginecólogo es bien conocido el llamado Test de Schiller, en el que al embadurnar el cue- 
llo uterino con la solución iodo_iodurada de Lugol, el epitelio cervical normal que contiene glucógeno, adquiere una coloración carmelita oscuro o caoba, a cambio de que los sitios en donde este epitelio se ha transformado o desaparecido aparecen como zonas iodo-negativas. Este es un test clínico demostrativo de la carga de glucógeno del epitelio y su valor estriba en indicarle al examinador los sitios sospechosos en donde debe tomar las biopsias. Ya desde antes de la iniciación de este test de Schiller, Ascheim había llamado la atención sobre el estudio histológico del glucógeno en los epitelios uterinos, pero indudablemente ha sido Moricard (4) quien ha hecho énfasis sobre la importancia de tales estudios anatomo-patológicos y quien ha sido el propulsor de la técnica de la goma iodada como medio de discriminación y de selección en el estudio de las biopsias sospechosas de Carcinoma Intraepitelial. El insiste, y con razón, que hasta ahora nunca ha encontrado un corte de un epitelio en el que concomitantemente con las transformaciones de un Carcinoma Intraepitelial verdaclero, existiera una carga en glucógeno normal. Esto no quiere decir que todo epitelio en el que desaparezca el glucógeno es carcinomatoso.

En las seiscientas y tántas biopsias estudiadas para la realización de este trabajo, con el fin de investigar si la carga en glu. cógeno estaba ausente o en vía de desaparición, según la lesión que presentaba el cervix, hemos empleado la técnica aconsejada por Moricard (5), así: fijación en Bouin alcohólico preparado con

Acido pícrico, sal alcohólica saturada .. . . . 30 c. c.

Formol . . . . . . . . . . . . . . . . . . ... . . 12 c. c.

Acido acético .................... . . . 3 c. c.

Habitualmente se deja el tejido en este líquido durante 24 a 48 horas. Después se pasa al alcohol absoluto y xilol, parafi. na, etc. Luego se colorea con goma yodada, la cual se prepara de la manera siguiente:

Goma arábiga $\ldots \begin{array}{llllllllllll} & \ldots & \ldots & \ldots & \ldots & \ldots & \ldots & \ldots & 50 & \mathrm{gms} .\end{array}$

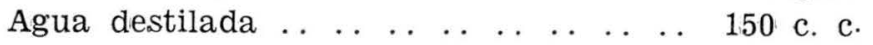

Esto se disuelve al calor, se filtra dos o tres veces y cuando está fría se agrega un gramo de yodo y tres gramos de yoduro de potasio disuelto en un centímetro de agua. La solución se conserva sin alteración de tres a cuatro semanas. 
En el tejido normal se aprecia al microscopio que el glucógeno toma un color carmelita caoba y un color amarillo claro, el color del Bouin, donde no existe glucógeno. En el epitelio patológico puede o no existir glucógeno. En las praparaciones del cuello de la niña de cinco años mencionada antes (Figura No I y IA y IB). No se demostró nada de glucógeno. Esto nos hace apreciar la consabida noción de que para que se manifieste la presencia de glucógeno es necesario que haya obrado sobre el epitelio una cierta cantidad de hormona estrogénica.

Es obvio mencionar que junto con la goma yodada hemos hecho coloraciones de cortes simultáneos con hematoxilina-eosina $u$ otras coloraciones especiales.

\section{Las lesiones distróficas del cervix}

Hace un par de décadas cuando la noción del Carcinoma Intraepitelial era desconocida, la definición de un carcinoma cervical era clara. Una lesión era cancerosa porque había invasión al estroma o no lo era por la ausencia de esta invasión. La deli. mitación era neta. Actualmente la modificación de este criterio y la aceptación de la existencia del carcinoma intraepitelial nos presentan una serie de problemas aún no dilucidados, así el criterio histológico del carcinoma intraepitelial mismo se presta todos los días a discusiones entre patólogos de reconocida talla. Por otra parte existe un gran conjunto de lesiones cervicales en las que las modificaciones estructurales del epitelio recorren toda la gama de irregularidades de estratificación, atipias, hipercromatismos, etc., poniendo en guardia y dejando la duda en la mente del observador. Son estas lesiones distróficas, diagnosticadas erróneamente, con frecuencia, como carcinomas intraepi. teliales verdaderos a las que nos queremos referir. Aceptamos la definición de Moricard (4) de que "estas lesiones no son cancerosas, es decir, que citológicamente no se acompañan de proliferación con anomalías mitóticas y que clínicamente no dan metastasis ni rcinciden después de la extirpación local". No pretendemos en los párrafos que siguen agotar el tema y estamos conscientes de que vamos a disentir con muchos conceptos, pero tratándose de lesiones aún en estudio, hemos creido de valor el somero repaso que presentamos. Fero, antes, es menester que hagamos un pequeño aparte respecto a los términos distrofia y displasia. Etimológicamente distrofia significa: error o mal en la alimentación y el crecimiento y el diccionario de la lengua lo define como "es- 
tado patológico que afecta a la nutrición y al crecimiento". Dis. plasia significa: error en el tejido. Así cualquiera de los dos términos sería adecuado para distinguir el conjunto de lesiones que nos ocupa. Sin embargo, como desde hace algún tiempo un buen número de autores en especial norteamericanos (9) han dado en Jamar Displasia únicamente a la lesión que, describiremos más adelante como Hiperplasia o Hiperactividad Basal y lo han hecho sinónimo de ella, hemos escogido por esto al igual que los autores europeos, en especial franceses (4), el término de Distrofias para englobar todo el conjunto de iesiones.

Metaplasias.-Lesión banal frecuentemente encontrada; consiste en la diferenciación dé un epitelio cilíndrico en pavimentos o a la inversa. La metaplasia escamosa especialmente la de las glándulas endocervicales ocasionalmente da lugar a confusión pero en ella como bien lo describe Marsh (9), a pesar de que en los estados tempranos hay poca o ninguna tendencia a formar capas diferenciadas, las mitosis son normales; no hay anormalidades nucleares notorias ni células discarióticas y es posible encontrar restos del epitelio columnar que tapizaba previamente las glándulas. Los patólogos alemanes acuñaron el término de "epidermización" (3) para muchas de estas metaplasias. Los pólipos en. docervicales la muestran con buena frecuencia.

En cuanto al contenido en glucógeno, presentamos como ejemplo uno de los muchos casos encontrados en las enfermas estudiadas en el Instituto de Cancerología: paciente de veintinueve años que consultó por flujo vaginal blanco-amarillento, el reporte-histopatológico (No 11.636) fue de metaplasia (Figuras № 2 y 2A), el glucógeno existía en algunos sitios y en otros había desaparecido. El tratamiento consistió en una electrocoagulación.

Novak (24) y muchos otros han insistido sobre la banalidad de este tipo de lesión que no puede ser considerado como lesión precancerosa, aunque a veces la proliferación es acentuada. Seguún Fluhmann (22), es necesario distinguir dos tipos de metaplasia escamosa: una regenerativa ocasionada por traumatismo o inflamaciones y que constituye un proceso de reparación epitelial y otra originada como resultado directo de un estímulo hormonal estrogénico intenso y cuya existencia ha sido comprobada experimentalmente tanto en humanos como en roedores. Fista última ha sido llamada prosoplasia (Nesbitt) (17) cuando se encuentra un epitelio altamente diferenciado. 
Leucoplasias.-Lesiones clínicamente diferenciables a sim. ple vista o con el colposcopio, se muestran como lo indica su nombre en la forma de placas blanquecinas. Placas gruesas cornificadas, hiperkeratinizadas, que recubren un epitelio activo inmaduro, como dice Moricard (4) con la formación de un estrato granuloso en las capas superficiales, con gránulos oscuros que han sido interpretados como de eleidina o de Querato hialina y puentes intercelulares notorios. Se asocia usualmente a un cierto grado de hiperplasia basal anormal. Por esto el término de leucoplasia encierra muy distintos grados de anormalidad y los conceptos a ella difieren enormemente. Si recordamos los trabajos originales de Hinselmann, para él toda leucoplasia representaba un estado precanceroso, a cambio de que Meyer, Novak (23) y muchos otros la consideran como una lesión banal ya que son pocos los casos desarrollados sobre la base de una leucoplasia e insisten en que hay "tanta justificación para considerar la leucoplasia como una lesión precarcinomatosa, como que por el hallazgo ocasional de carcinomas en pólipos se pueda afirmar que los pólipos son precursores de cáncer". Sin embargo es que como hemos dicho, se han abarcado bajo esta denominación desde simples hiperqueratosis hasta lesiones casi infiltrativas. Anote. mos que el término paraqueratoris (1) hace relación a la queratinización imperfecta con retención del núcleo en las capas superficiales del epitelio. La capa granulosa se encuentra ausente en las áreas de paraqueratosis. $\mathrm{Y}$ así se llama también paraleucoqueratosis o leucoparaqueratosis a aquellas lesiones iodo-negativas con paraqueratosis de los estratos superficiales y a la leucoplasia verdadera. Hertig (25) la designa con el nombre de leucokeratosis o leucohiperqueratosis. En casos de prolapso (en donde la leucoplasia es banal) se presentan digitaciones que pene. tran profundamente en el tejido conjuntivo por hiperacantosis; pero en ausencia de prolapso sí se encuentra una lesión leucopiásica en franca proliferación e hiperqueratosis y sobre todo si hay una hiperplasia basal notoria, esta lesión debe ser vigilada suidadosamente, extirpada y su cicatrización observada. Uno de nuestros casos presentaba la asociación de por sí interesante de carcinoma in_situ y leucoplasia.

Mencionemos también otro caso: mujer que consultó por hemorragias genitales de varios años de duración y en que la biopsia mostró una leucoplasia (Figuras III y IIIA) (Protocolo No 11.021) con gran cantidad de globos córneos y abundante glucó- 
geno, lo que es al parecer bastante raro ya que Moricard, tantas veces citado, afirma que generalmente hay desaparición completa del glucógeno. En el caso de la asociación con carcinoma insitu observamos dentro de la leucoplasia zonas con glucógeno y zonas desprovistas de él, pero no pudimos observar la amputación neta del glucógeno.

Hiperplasias.-En su forma más simple, la hiperplasia es el espesamiento del epitelio por aumento en el número de sus células, que se puede considerar como un proceso reaccional epitelial motivado por un proceso inflamatorio el cual produce una proliferación benigna del epitelio cervical relacionada muchas veces con un proceso de reparación. Sin embargo es éste el grupo más complejo, pues dentro de ellas es necesario considerar aquella serie de lesiones que algunos engloban bajo el término de displasia y que se conoce más comúnmente, sobre todo en la literatura norteamericana con el nombre de hiperactividad celular basal (Prickle Cell Hyperplasia) o hiperplasia basilar o mejor hiperplasia basal. En ellas puede haber o no aumento del espesor del epitelio. Puede haber o no presencia de glucógeno, de ahí que Moricard (4) las divida en hiperplasias con carga de glucógeno abundante e hiperplasia con carga de glucógeno regular c poca. Lo que llama la atención es que, como su nombre lo indica, la actividad de la capa basal en empalizada aumenta y en vez de existir una capa basal neta de células perpendiculares al estroma, ellas reemplazan en todo o en parte al resto de capas del epitelio resultando así una pérdida de la estratificación normal del epitelio con hipercromatismo y muchas veces con irre. gularidad o fusión de núcleos y aumento de mitosis.

Estas lesiones son las que han dado lugar a buen número de confusiones y de controversias pues realmente muchas de ellas están en el límite de las neoplasias, ya que existe toda una gama de variaciones entre el extremo de la línea que todo patólogo consideraría como lesión benigna, constituído por una hiperplasia basal parcial con núcleos y mitosis normales y poco polimorfismo y el otro extremo en que la hiperplasia basal ha cogido todo el espesor del epitelio como pérdida de la estratificación, hipercromatismo, polimorfismo, y aumento de las mitosis. Solo nos faltaría agregar en estas últimas, discariosis y atipias, para tener el cuadro de un carcinoma intraepitelial. Se comprende pues que el diagnóstico diferencial sea en repetidas ocasiones extremadamente complejo. Aquí es donde nos presta mayor ayuda 
como métodọ de discriminación la goma iodada para descubrir el contenido del glucógeno.

En las biopsias estudiadas para este trabajo encontramos varios casos de hiperplasia. Presentamos algunos de ellos: Uno el de una mujer de cuarenta años que consultó por flujo vaginal amarillento, con diagnóstico clínico de Tricomoniasis, la biopsia mostró hiperplasia y queratosis exocervical (Protocolo No 11.605) (Figuras IV y IVA). El glucógeno estaba disminuído.

Otro caso es el de una paciente que venía presentando hemorragias genitales ligeras por espacio de 4 años. La biopsia mostró hiperplasia con ausencia del glucógeno. La lesión fue electrocoa_ gulada simplemente y la enferma evolucionó hacia la curación (Protocolo No 11.370) (Figura V y VA).

Un caso de cervicitis pseudo erosiva asociada a hiperplasia fue el de una enferma de veintiocho años que consultó por flujo hemático. El estudio de la biopsia dio como resultado hiperplasia y cervicitis. El glucógeno ausente en algunas zonas estaba en otras abundante (Protocolo No 11.265) (Figura VI y VI A.).

Galvin Jones y Telinde (18) sobre 197 casos de Hiperactividad Basal, clasificados en tres grados de acuerdo con la intensidad de esta hiperactividad, encontraron que en 33 o sea $17 \%$ existía un carcinoma no invasor. La importancia de la clasificación del grado de hiperplasia basal resalta por el hallazgo de que solo un $2 \%$ de aquellos casos catalogados como grado o estado I de hiperactividad basal eventualmente probaron ser carcinomas intraepiteliales, a cambio de que un $65 \%$ de aquellos en el grado III, el más avanzado de hiperactividad basal, finalmente mostraron un carcinoma in-situ.

Hiperplasia glandular.-Dentro de los protocolos anatomopatológicos de las biopsias cervicales estudiadas en el Instituto no es raro encontrar este término. El patólogo se refiere con él a aquellos cortes en los cuales existe un aumento marcado de glándulas cervicales, sin que necesariamente haya aumento del espesor del epitelio glandular. Esto es frecuente en las Cervicitis Polipoides. En el caso que presentamos existía también Hiperplasia epitelial concomitante (Figuras VII y VII-A.).

Anaplasia regenerativa.-Es posible encontrar en el epitelio en vía de regeneración de un cuello erosionado pequeñas placas de núcleos hipercromáticos y atípicos, con poca estratificación y rodeados de cambios inflamatorios. Es a esta lesión, que puede 
dar lugar a sospechas de difícil interpretación cuando el corte histológico recae precisamente sobre ella, a lo que Hertig (25) ha llamado Anaplasia Regenerativa o de Reparación epitelial.

Por otra parte el término de anaplasia es frecuentemente usado para describir grupos de células inmaduras o mal diferenciadas con núcleos hiperactivos e irregulares.

Hipoplasias.-Esta lesión en la que el espesor del epitelio es. tá disminuído se origina por trastornos endocrinos (castración, hipoestrogenismo, etc.), o de receptividad misma del epitelio (metrosis de receptividad de Moricard) (5). La mencionamos únicamente porque en ella se pueden encontrar núcleos desiguales, pero es obvio que no hay ningún signo de proliferación o crecimiento que la acerque a las lesiones que hemos comentado previamente.

\section{Modificaciones del epitelio cervical en el embarazo}

Ya desde 1927 Stieve y luego Hofbauer en 1933 (citados por Nesbitt) (17) demostraron que durante el embarazo ocurren modificaciones notorias tanto del epitelio glandular como del epite'io pavimentoso del Cervix. La importancia de tales modificaciones ha sido revivida durante los últimos años por el hallazgo de verdaderos Carcinomas Intraepiteliales concomitantes con la preñez y por el hecho de que varios de estos casos diagnosticados como Carcinomas In-situ regresaron o parecieron regresar en el puerperio.

Los cambios endocervicales son bien conocidos y establecidos. El epitelio glandular prolifera intensamente y los espacios glandulares se distienden y llenan de moco para llegar a formar el Ilamado tapón mucoso, haciendo entonces protrusión hacia afuera del canal endocervical. Como lo anota Eastman (21) existe al igual que siempre que hay eversión del epitelio glandular, una tendencia del epitelio escamoso a recubrir rápidamente este epitelio glandular expuesto, por procesos de epidermización y metaplasia. Estos procesos de epidermización se rodean frecuentemente de infiltración notoria por células inflamatorias.

En el exocervix, el epitelio pavimentoso sufre también modificaciones, a más de las anotadas de epidermización, atribuídas por la mayoría de los autores al aumento progresivo y sostenido de los niveles hormonales en especial del nivel estrogénico. Murphy y Herbut (13) en un estudio de cincuenta biopsias tomadas 
en embarazadas, dividieron estas alteraciones en dos grupos: 1) Aumento de espesor del epitelio escamoso, hecho sobre todo a expensas de las capas superficiales. Esta hiperplasia fisiológica es constante en todos los especímenes; 2) Aumento de la actividad de la capa basal en un seis por ciento de los casos.

Para Nesbitt (17) sin embargo, esta Hiperplasia Basal ocurre en veinte por ciento de los casos, pero la hiperactividad basal en la mitad de los casos estaba localizada únicamente en el epitelio endocervical. Eastman (21) hace notar que Rosenthal mostró que los mismos cambios se suceden en el cervix fetal. Según Nesbitt (17) parece que hay un aumento en la incidencia de hiperactividad basal en los embarazos subsiguientes de acuerdo con el grado de hiperactividad en el embarazo inicial.

Nesbitt y Hellman (26) sobre trescientas embarazadas encontraron los siguientes cambios: "Hiperactividad basal del ectocervix en $6,8 \%$ de los casos y epidermización superficial en $10,7 \%$. Hiperplasia glandular en $28,7 \%$. Hiperplasia glandular epitelial en $47,4 \%$. Hiperplasia adenomatosa en $44,1 \%$. Epidermización en $62,7 \%$. Y Carcinoma Intraepitelial en $0,66 \%$ ".

Hellman (16) ha llamado células de Reserva (Reserve Cells) a células basales del endocervix y ha hecho notar que estas céIulas por sus potencialidades múltiples pueden llegar a mostrar cambios atípicos de hiperplasia muy similares si no idénticos al carcinoma intraepitelial, cuando se las ha sometido a un estímulo estrogénico intenso ya experimentalmente, ya en el curso de una preñez, o ya cuando existe un tumor de la granulosa. Son estas 'esiones las que son más susceptibles de regresar. En cambio las hiperplasias basales del ectocervix que han cogido todo el espesor del epitelio (hiperplasias basales. Grado III de Nesbitt), persisten en buen número de casos después de qué el embarazo ha pasado. Así Greene (14) y Peckhan (15) insisten en que estas lesiones no son cambios específicos inherentes al embarazo sino hallazgos incidentales de verdaderas hiperactividades epiteliales fustigadas, tal vez por el embarazo, pero no ocasionadas por él. Sobre 14 casos de Greene (14) en los que se había hecho el diagnóstico de Carcinoma intraepitelial durante el embarazo, la lesión persistió en 12 después de la terminación de la preñez. Así mismo en los 19 casos de Peckhan (15), que él divide en Hiperplasias basales atípicas y Lesiones Sospechosas (es decir, lesiones que no merecen aún por sus características la categoría de carcinomas intraepiteliales pero en los que la anomalía era aun más 
intensa que una hiperplasia basal atípica), la mayoría de las lesiones persistieron y uno de ellos progresó a un Carcinoma Intraepitelial en un período de tres años, a través de dos embarazos. El reverso de la medalla, son los 7 casos de Epperson (12) Nesbitt y Hellman (26) en los que alteraciones que en la no embarazada se hubieran catalogado como Carcinoma Intraepitelial, regresaron después del embarazo en controles hasta de veintidós meses después del parto.

Como se deduce de los anteriores párrafos el acuerdo entre los investigadores no está hecho y si en la no embarazada para hacer el diagnóstico de un verdadero carcinoma intraepitelial necesitamos repetidas biopsias, amputación del cuello, etc., en la embarazada tenemos que recurrir no solo a los controles periódicos de biopsias, citología, etc. durante el embarazo, sino has. ta verificar la persistencia de la lesión en el puerperio tardio antes de tratar la enferma definitivamente.

De nuestra propia observación poco o nada podemos decir respecto a estas lesiones durante el embarazo, por varios motivos, el principal de los cuales es que el material que usamos para este trabajo no provino de un centro de maternidad sino en contadísimos casos. Solo presentamos la microfotografía de una biopsia de cuello en una embarazada en la cual existía una hiperplasia moderada. Figura VIII y VIIIA.

\section{Carcinoma intraepitelial. Investigación del glucógeno}

A pesar de que por definición simple el término carcinoma intraepitelial o in-situ se refiere al "cuadro histológico presentado por el epitelio cervical en el que las células individuales a través de todo el espesor de las capas epiteliales presentan las mismas características de las del carcinoma invasor" como hemos dicho antes el criterio histológico del carcinoma intraepitelial no ha llegado a una interpretación exacta. Así lo demuestran las encuestas experimentales hechas en Europa y Estados Unidos en las que sobre una serie de cortes histológicos de carcinomas intraepiteliales, enviados a diferentes patólogos de reconocida talla, solo estuvieron de acuerdo en el diagnóstico final en un porcentaje tan reducido como 5 o $10 \%$.

Por esto queremos transcribir, casi a la letra, dos conceptos. El primero son las conclusiones del Laboratorio de la Clínica Ginecológica de la Universidad de París (4), dice: "El diagnóstico no puede estar fundado sino sobre grupos de criterio, de los cuales los más importantes son: 1) Anomalías celulares: a) Anapla- 
sia: irregularidad de talla y forma de las células, basofilia del citoplasma, disminución o desaparición de glucógeno, aumento de la relación núcleo-citoplásmica.

b) Atipias nucleares: gigantismo, multiplicidad de los núcleos polilobulados, anomalías nucleares tales como aumento de volumen o de número.

c) Anomalías de la proliferación: cuantitativa: mitosis en número excesivo. Cualitativa: mitosis anormales, anomalias de posición de los cromosomas, posibilidad de poliploidias. Topográficas: presencia de mitosis en las capas superficiales.

\section{Anomalías arquitecturales:}

a) Discontinuidad entre el revestimiento normal y el revestimiento patológico por razón de las anomalías descritas.

b) Trastornos estructurales con desproporción del espesor relativo de las diferentes capas.

Cuando todas estas características coexisten el diagnóstico del carcinoma intraepitelial es probable pero ninguna de ellas in. dividualmente es especifica.

El segundo concepto-criterio es el de Memoir Marsh (9) quien divide los carcinomas intraepiteliales en "(1) tipo anaplástico que recuerda los estados avanzados del carcinoma invasor franco.

2) Tipo inmaduro o poco diferenciado caracterizado por ausencia de puentes intercelulares, bordes celulares esfumados, núcleos apelotonados como resultado en el cambio de la relación núcleo-citoplásmica, núcleos hiper o hipo cromáticos, mitosis anormales, estratificación perdida aunque puede haber esbozo de ella, y 3) Tipo maduro o bien diferenciado que posee las mismas características del anterior excepto porque es una lesión cornificante con capa de queratina inmediatamente por encima de la capa granular".

En los casos de carcinoma intraepitelial, estados $O$, de este grupo de biopsias, en los que investigamos la carga de glucógeno hallamos ausencia de glucógeno, dato sobre el cual ya hemos insistido y acerca del que Moricard (6) ha recalcado la importancia. Sin embargo, a diferencia de este autor francés no encontramos en la mayoría de los casos, la amputación brusca, neta del glucógeno tan nítida y característicamente como él lo des. cribe. Esto no quita valor al papel discriminativo de la goma iodada pues basta con que no haya glucógeno, desaparezca él gradual o bruscamente. Figura N. IX y IXA. Protocolo 11.416. 


\section{BIBLIOGRAFIA}

1. LOPEZ-ESCOBAR GUIOLERMO.- "Diagnóstico Precoz del Cáncer" (Citología y cáncer intraepitelial). Repertorio de Medicina y Cirugía. Hospital de San José. Vol. IV, No 5. Julio /49 P.: 261-269.

2. LOPEZ-ESCOBAR GUILLERMO. et. al.- “Tratamiento del Carcinoma del Cervix Uterino. Universitas. V. III. No 11. 1951 P.: 363_410.

3. LEAÑO FLOREZ S.-"Displasias y Carcinoma In-Situ del Cuello Uterino". Tesis de la Universidad Javeriana. 1956.

4. FUNCK_BRENTANO P. et al.- "L' Epithe!ioma Pavimenteux Intraepithelial du Col Uterin". Bull de la Fed Societes de Gyn. et Obst. Vol. IV. No 1 bis. 1952. P.: 80-144.

5. R. MORICARD.- “Diagnostico Differentiel et des Easts Dystrophiques et des Epitehliomas Pavimenteux Cervicaux". Gynec. et Obstetrique. V 51. No 1. 1952. P: 1-22.

6. R. MORICARD.- "Reflexions sur la Definition du Stade O Des Epitheliomas du Col. Uterin". Bull de la Fed. Societes de Gynec. et d'Obstetrique. V. 4. No 5 1952. P.: 844-853.

7. FUNCK BRETANO P. y MORICARD R.-"Metaplasie Pavimenteuse Benigne complete des Glandes Endo-cervicales et probleme du Diagnostique Differentiel avec l'epithelioma pavimenteux invasif du Col". Bull. de la Fed. Societes de Gynec et d' Obstetrique. V. 4 No 2. 1952. P.: 213_217.

8. FUNCK-BRENTANO et al.-- "Diagnostic et traitement de l' Epithelioma Pavimenteux Intra_epithelial du Col Uterin". Semaine des Hop. de París. A. 28 No 71 . Sep. 26/52. P.: 1-10.

9. MARSH Mr. R. y HELLMAN L. M.- "The Value of an Intensive Pelvic Cancer Detection Program". Surg. Clin. of North Am. 1953. P.: 525. W. B. Saunders \& Co. Ed. Filadelfia.

10. MEIGS J. V.- "Carter Monographs on Surgery". The Nelson and Sons Ed. N. Y. 1951.

11. DOUGLAS R. G. y FIM W/S.- "Early Recognition of Ca. of Cervix". Surg. Clin. of Norht Am. 1953. P.: 543-W/B. Saunders \& Co. Ed. Filadelfia.

12. EPPERSON J. W. et al.-"The morphological changes in the Cervix during Pregnancy". Including Intra-epithelial Ca. Am. J. of. Obst. and Gynec. V. 61. No 1 Jan. 51. P.: 50-61.

13. MURPHY E. J. y HERBUT P. A.-"The Uterine Cervix during Pregnancy”. Am. J. Obst. \& Gynec y 59. No 2 Feb./50. P.: 384_390.

14. GREENE et al.-"Preinvasive Carcinoma of the Cervix during Pregnancy". Surg. Gyn. Obst. V. 96. No 1 Jan /53. P.: 71-81.

15. PECKHAN B. et al.- "The Relation of Pregnancy to Abnormalities of the Cervical Epithelium". Surg. Gyn. Obst. V. 99. No 4. Oct./54. P.: 401-412.

16. HELLMAN et al.- "Some Factors influencing Proliferation of Reserve Cells in Human Cervix". Am. J. Obst. \& Gynec. V. 67 April L54. P.: 899-915. 
17. NESBITT R. E. L.-“Basal_Cell Hyperactivity of the Cervix in Pregnancy with Postpartum Follow-up". Obst. Gyn V VI. 3 Sept./55 P.: 239-253.

18. GALVIN G. A. et al.- "The significance of Basal-Cell Hyperactivity in Cervical Biopsies". Am. J. Obst. \& Gynec. V. 70. No 4. Oct./55 P.: 808-821.

19. PEIGHTAL T. C. et al.- "Conservative Treatment of Carcinoma In Situ of the Cervix", Am. J. Obst. \& Gynec. V. 69. N 3. March./55. P.: 547_557.

20. CARTER B. et al.- "Clinical Problems in Stage O (Intraepithelial) Cancer of the Cervix". Am. J. Obst. \& Gynec. V. 71. № 3. March. /56. P.: $634 \_652$.

21. EASTMAN N. J.-"Williams Obstetrics". Appleton-Century Crofts Inc Ed. N. Y. 1956. P.: 223-225.

22. FLUHMANN C. F.-“Comparative Studies of Squamous Metaplasia of the Cervix Uteri”. Am. J. Obst. \& Gynec. V. 68. 1954. P.: 1447.

23. NOVAK E.-“Gynecological and Obstetrical Pathology". W. B. Saunders Co. Ed. Filadellfia. 1940.

24. NOVAK E.-“Textbook of Gynecology". The Williams \& Wilkings Co. Ed. 1944.

25. HERTIG A. T. y MANSELL H.-"Meigs and Sturgis Progress in Gynecology". V.III Grune \& Stratton. Ed. N. Y. 1957.

26. NESBITT R. E. L. y HELLMAN L. M.-“The Histopathology and Cytology of the Cervix in Pregnancy". Surg. Gynec. \& Obst. V. 94. 1952. P.: 10. 


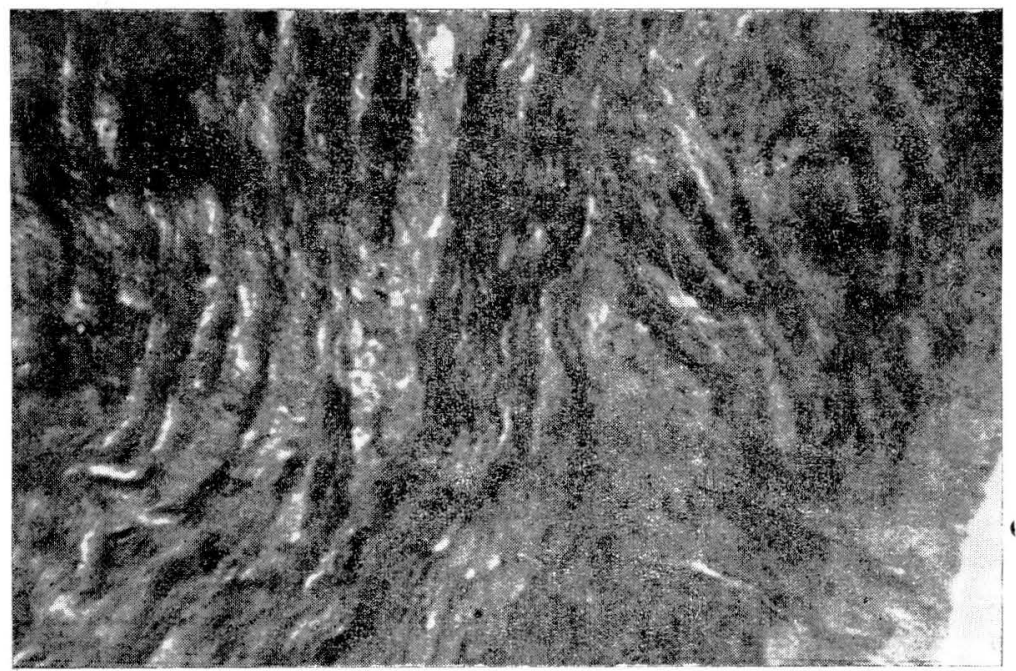

FicURA NUMERO I.-Cervix de una niña de cinco años (Hematoxilina-Eosina).

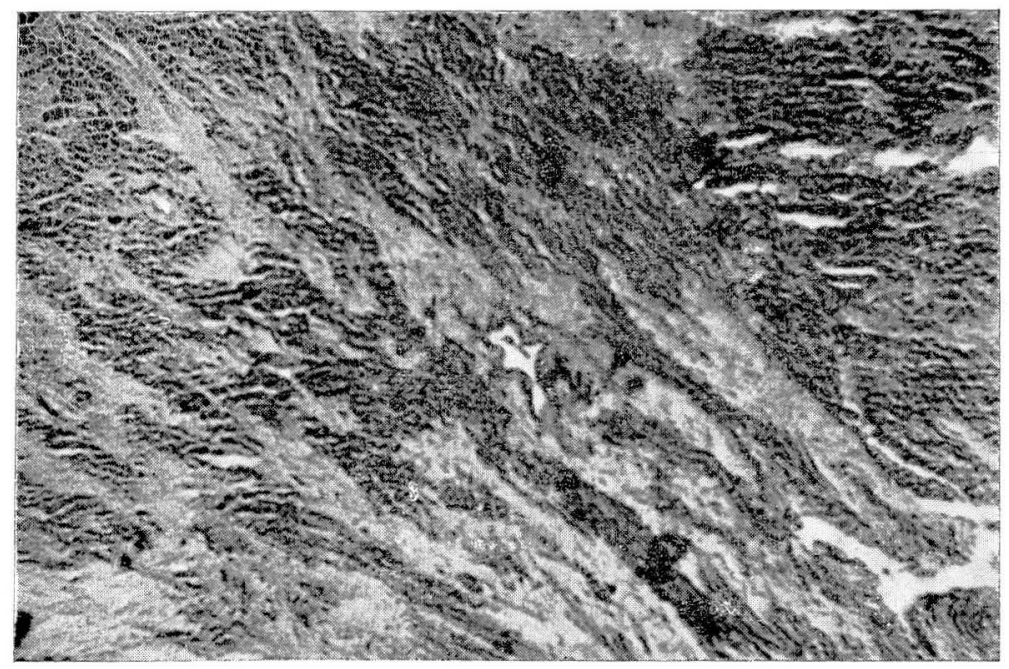

FIGURA NUMERo I-A.-Cervix de una niña de cinco años (Goma Iodada). No se demuestra glucógeno. 


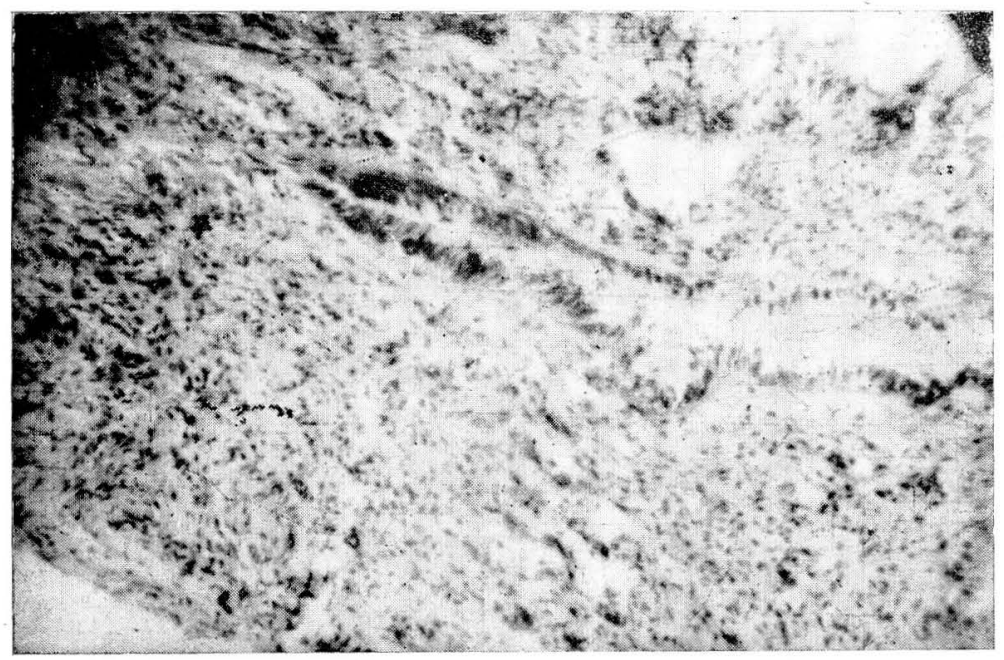

FIGURA NUMERO I-B.-Cervix de una niña de cinco años. Esbozo de glándula endocervical. 


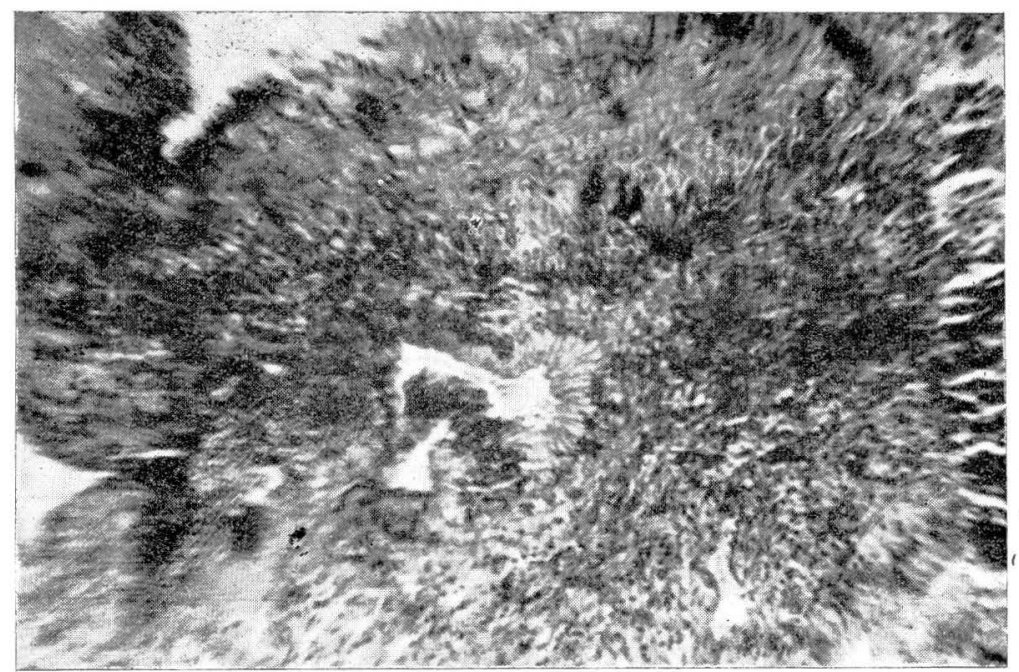

FIGURA NUMERO II.-Metaplasia cervical (Hematoxilina-Eosina) (Protocolo número 11.636). Nótese la glándula en el centro.

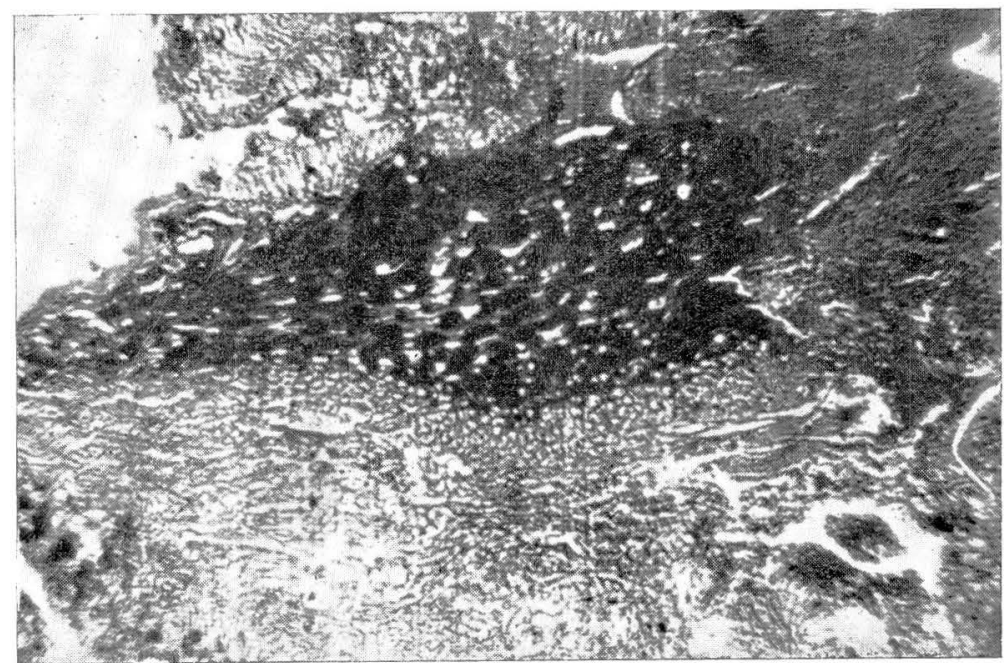

FIGURA NUMERO II-A.-Metaplasia cervical (Goma Iodada) (Protocolo número 11.636). La parte oscura en el centro corresponde a las células coloreadas con la goma iodada del epitelio pavimentoso dentro de una glándula. 


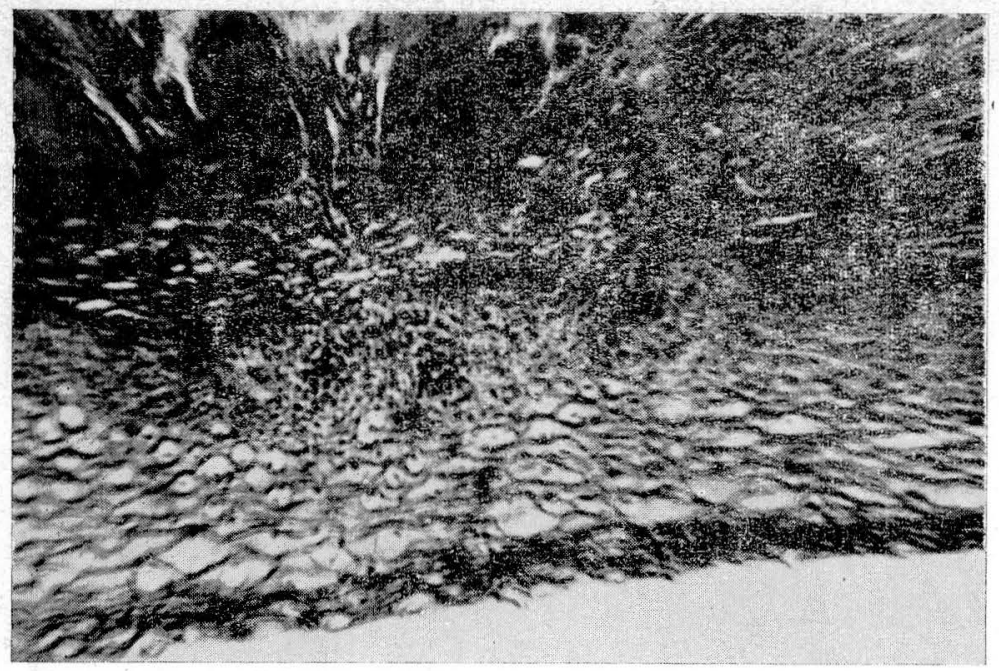

FIGURA NUMERO III.-Leucoplasia cervical (Hematoxilina-Eosina) (Protocolo número 11.021).

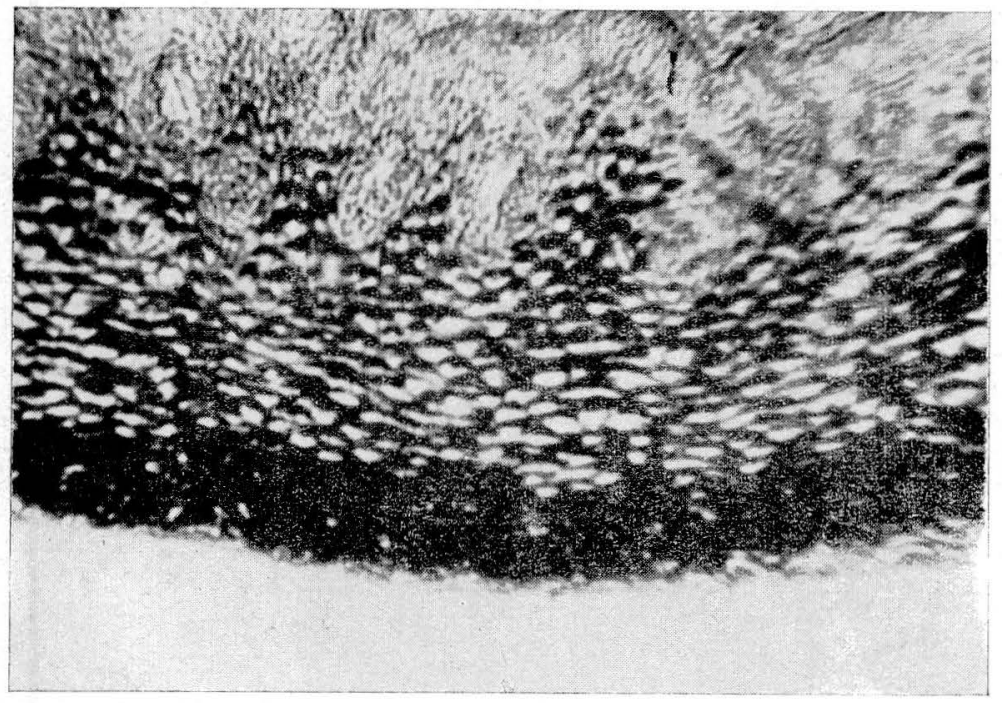

FIGURA NUMERO III-A.-Leucoplasia cervical (Goma Iodada) (Protocolo número 11.021). Existe abundante glucógeno que corresponde a la porción oscura de las células, difícil de hacer aparente en la fotografía en blanco y negro. 


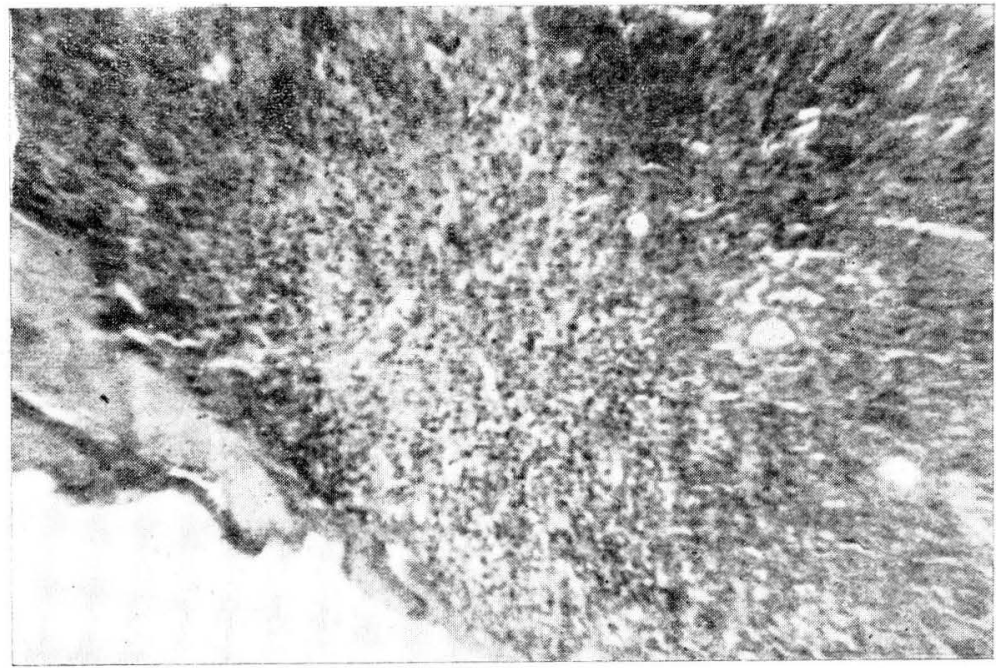

FIGURA NUMERO IV.-Hiperplasia y queratosis exocervical con tricomoniasis (Hematoxilina-Eosina) (Protocolo número 11.605).

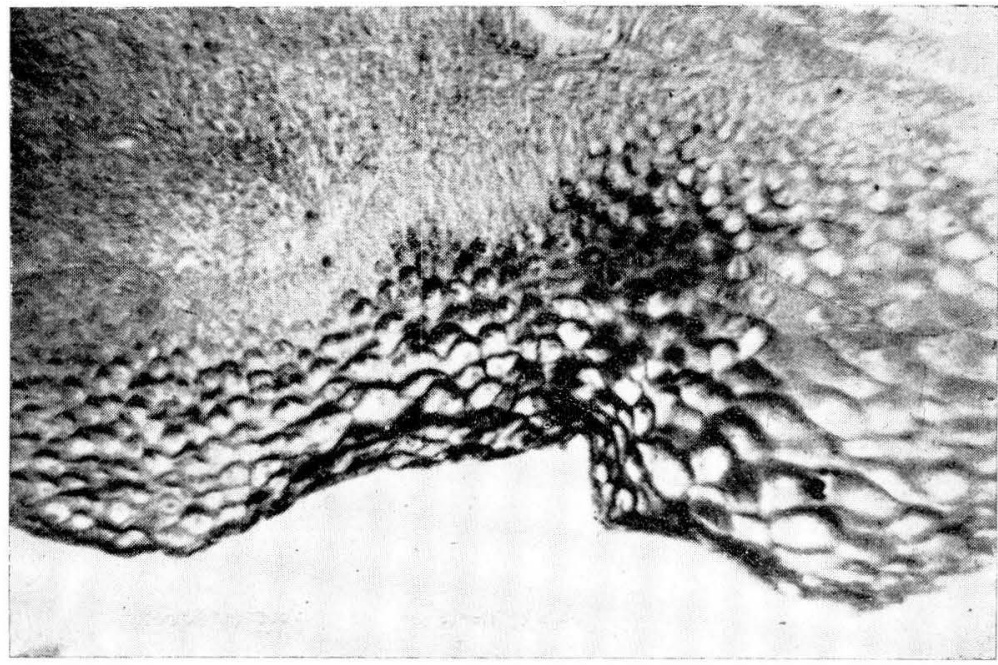

FIGURA NUMERO IV-A.-Hiperplasia y queratosis exocervical con tricomoniasis (Goma Iodada) (Protocolo número 11.605). 


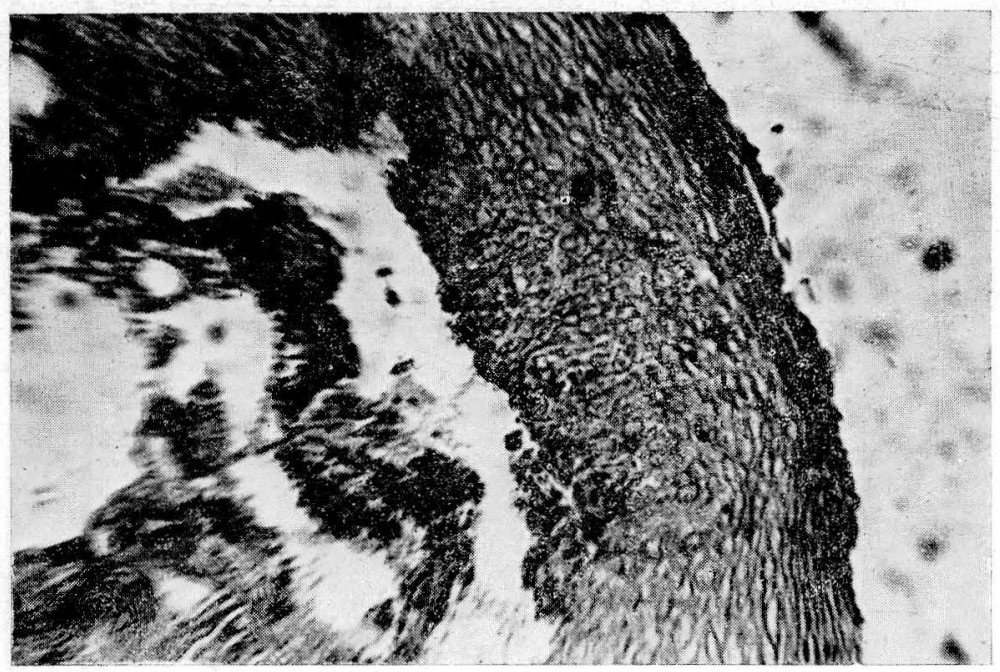

FIGURA NUMERO V.-Hiperplasia exocervical (Hematoxilina-Eosina) (Protocolo número 11.370).

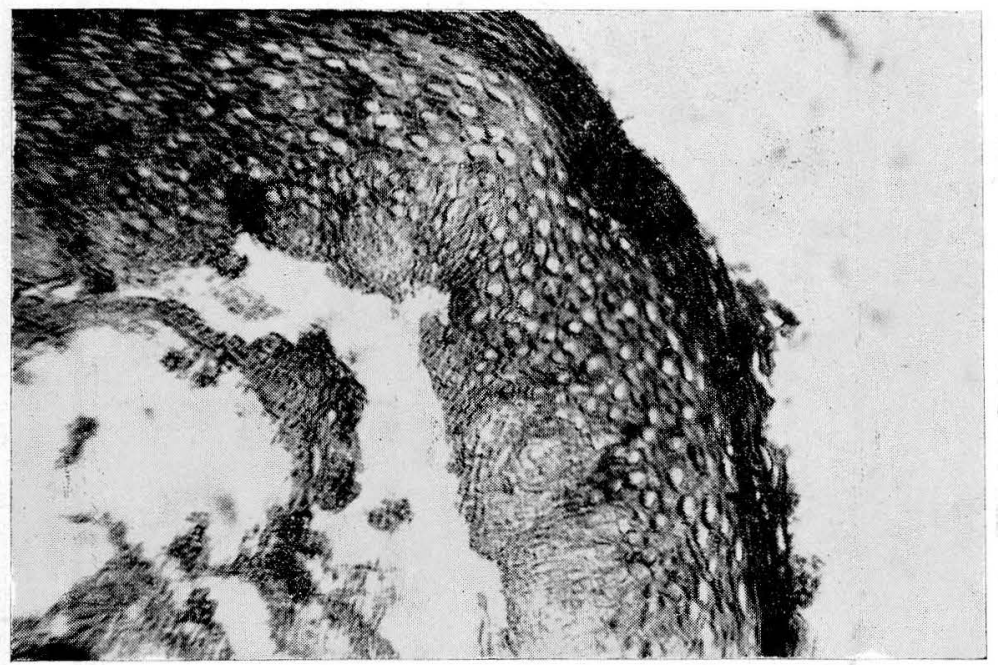

FIGURA NUMERO V-A.-Hiperplasia exocervical (Goma Iodada) (Protocolo número 11.370). Ausencia de glucógeno. 


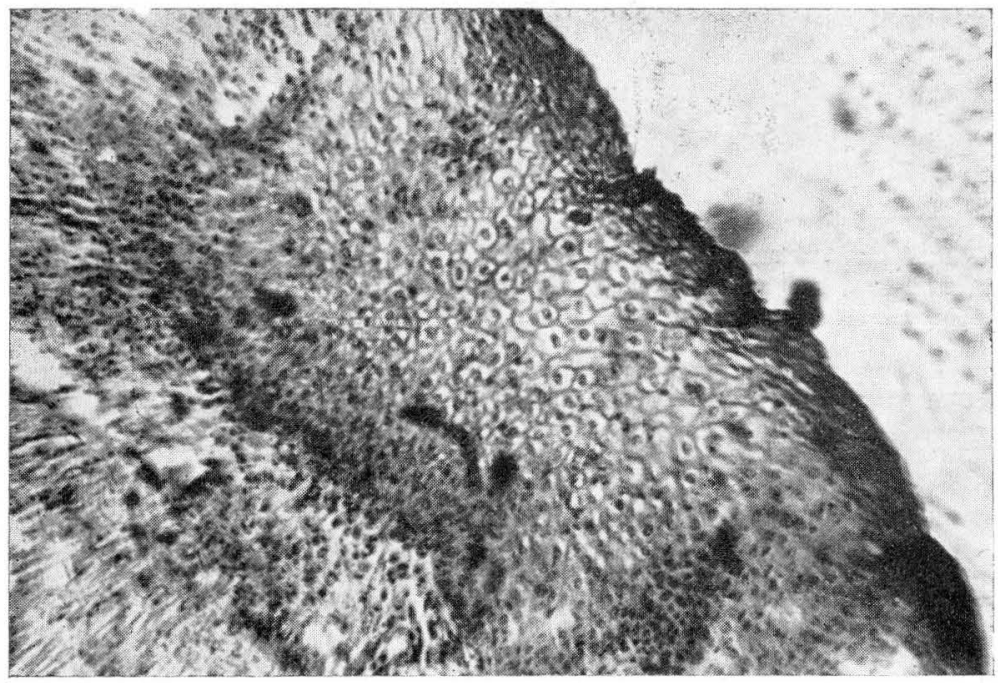

FIGURA NUMERO VI.-Hiperplasia y cervicitis (HematoxilinaEosina) (Protocolo número 11.265).

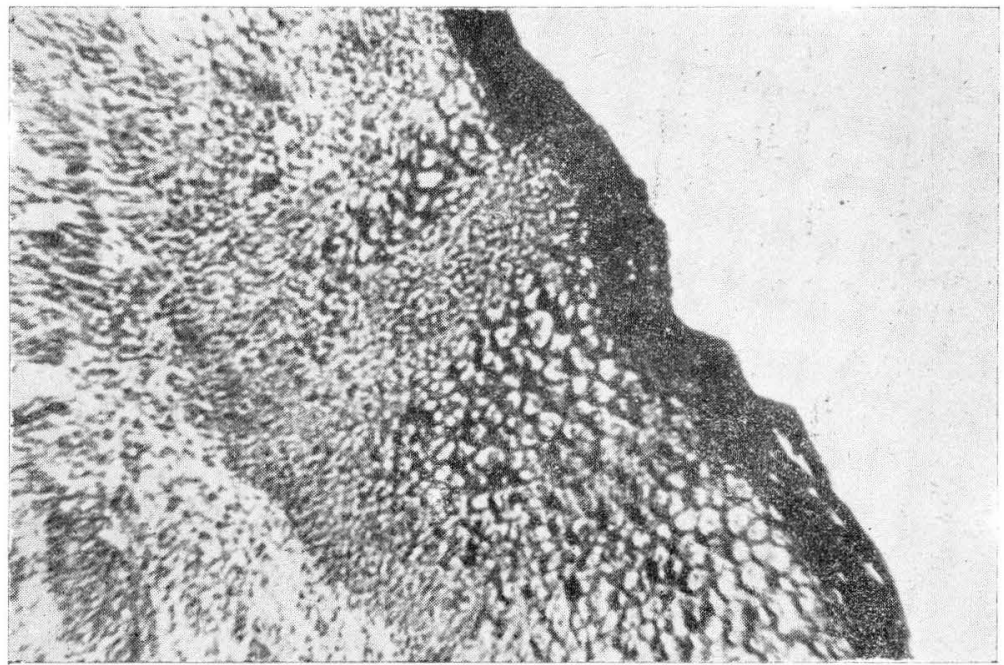

FIGURA NUMERO VI-A.-Hiperplasia y cervicitis (Goma Iodada) (Protocolo número 11.265). Glucógeno ausente en unas zonas, en otras abundante. 


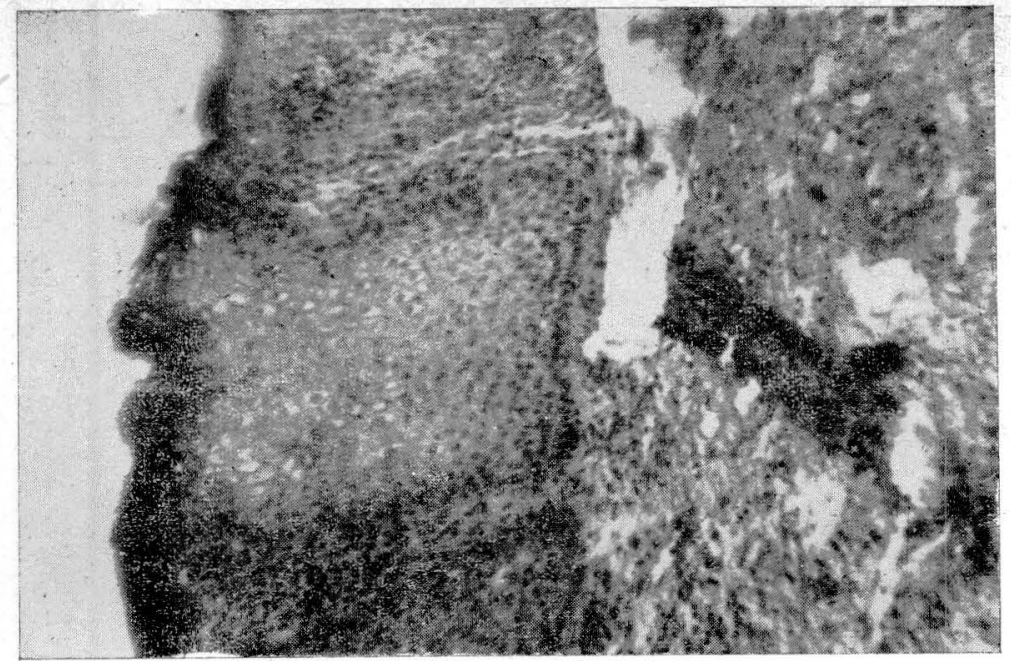

FIGURA NUMERO VII.-Hiperplasia glandular moderada (Hematoxilina-Eosina). Existe también hiplerplasia epitelial concomitante. El corte histológico está bastante dañado, pero en general los orificios corresponden a glándulas.

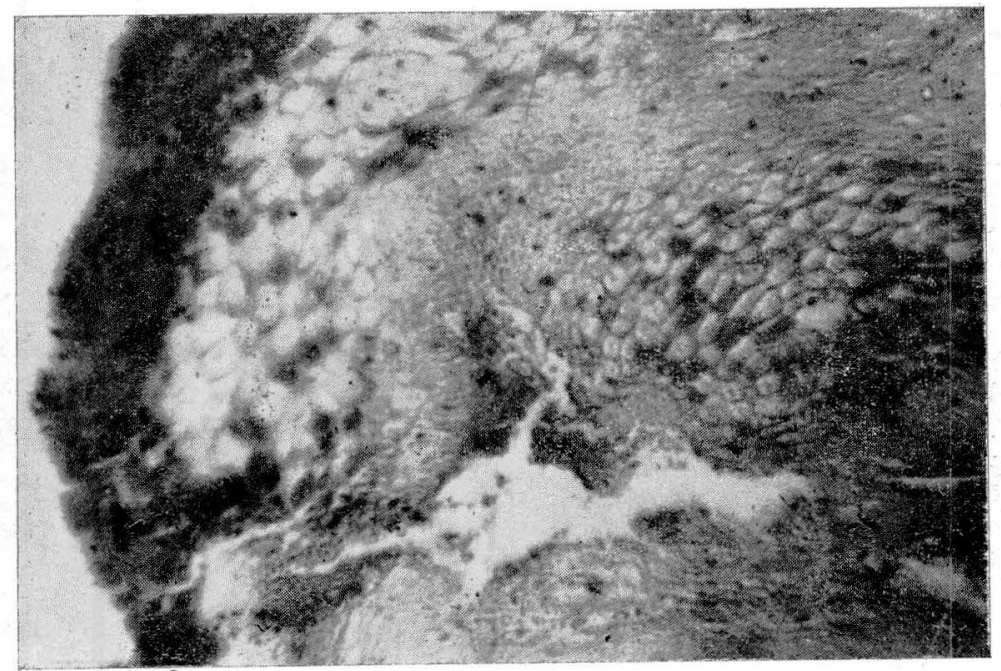

FIGURA NUMERO VII-A.-Hiperplasia glandular moderada (Gnma Iodada). 


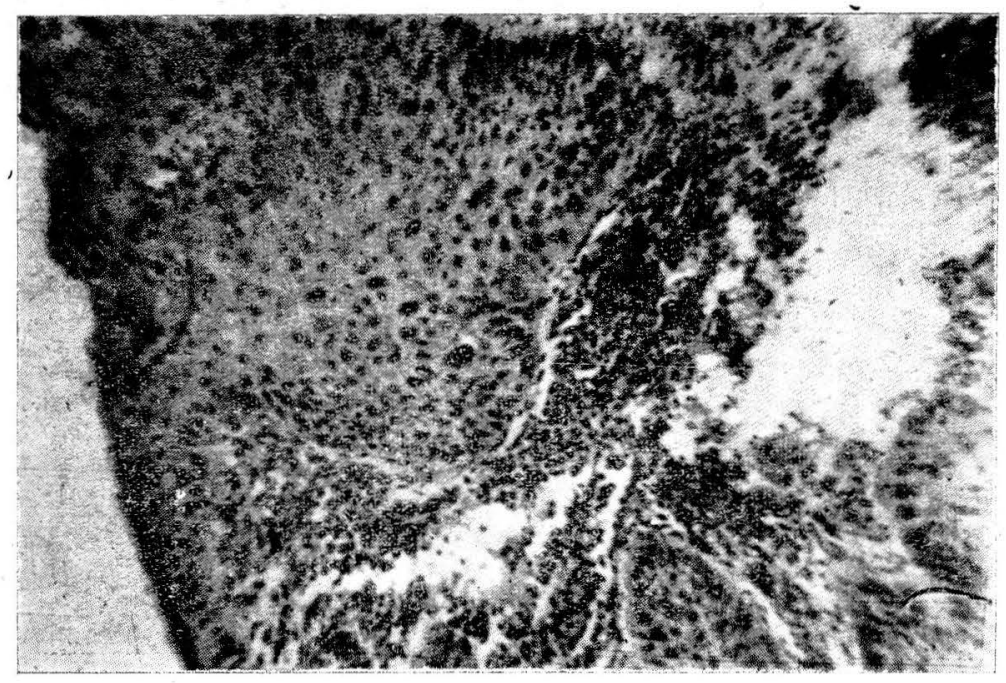

FIGURA NUMERO VIII.-Cervix en embarazo (Hematoxilina-Eosina). Nótese la hiperactividad basal ligera.

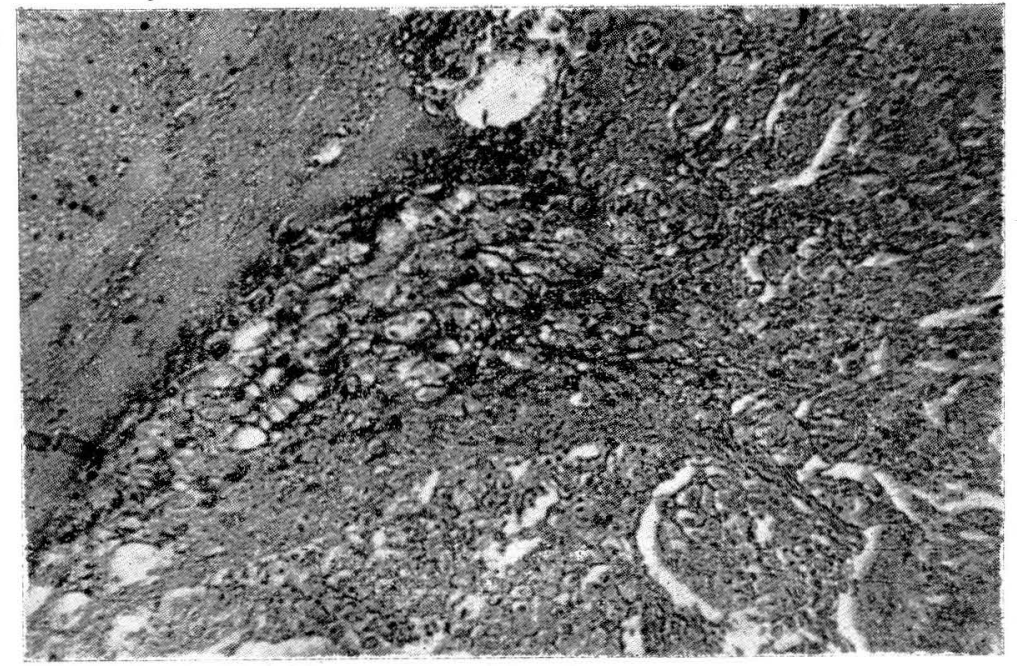

FIGURA NUMERO VIII-A.-Cervix en embarazo (Goma Iodada). 


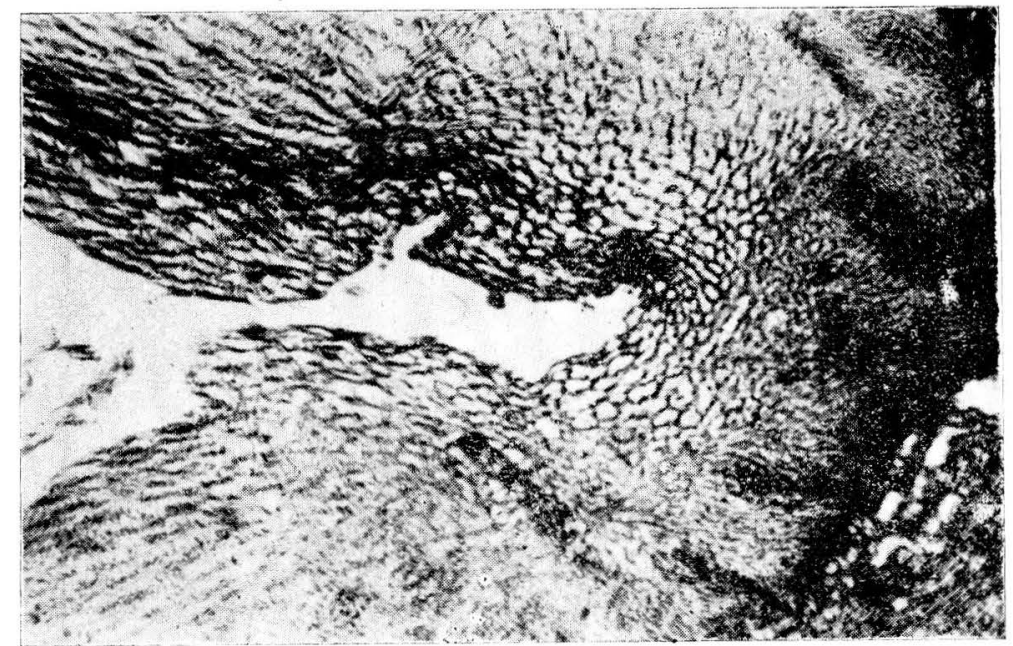

FIGURA NUMERO IX.-Ca. intraepitelial cervical (HematoxilinaEosina) (Protocolo número 11.416). Nótese la transformación gradual entre el epitelio normal en los dos tercios inferiores y el ca. intraepitelial en el tercio superior. La fotografía en blanco y negro no es tan diciente como la de color original.

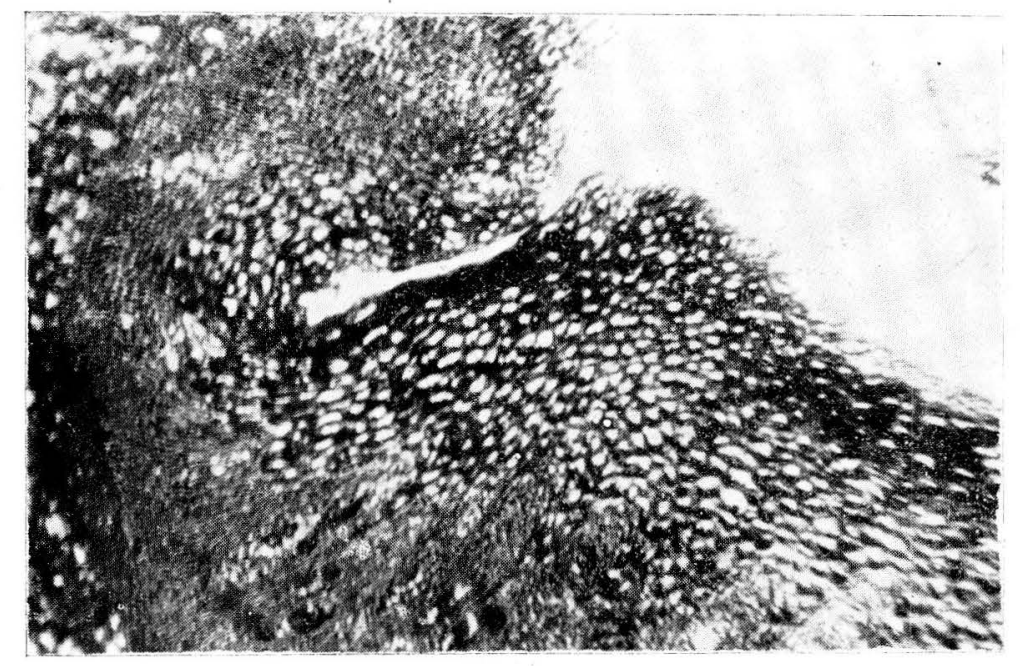

FIGURA NUMERO IX-A.-Ca. intraepitelial cervical (Goma Ioda(ia) (Protocolo número 11.416). La ausencia de glucógeno es bien visible en la fotografía en color original (conocidas son las dificultades para la publicación de fotografías en color entre nosotros). 